\title{
Uma mulher, muitas barreiras
}

Culpados.

CHOPIN, Kate.

Tra dução de Carmem Foltran.

Vinhedo, SP: Horizonte, 2005. 242 p.
Selecionada para figurarem uma coleção especialmente dedicada à presença da mulher na literatura - a coleção Mulheres e Letras da Editora Horizonte -, Kate Chopin, assim como as dema is a utoras previstas nessa proposta editoria l, teve de transpor barreiras para poder viver de sua literatura.

Kate Chopin (1850-1904) era uma mulherà frente de seu tempo. De escrita elaborada na forma e ousada no conteúdo, Chop in surpreende pela habilidade narrativa e pela coragem em lidarcom temas polêmicos. Já no final do século XIX, impõe corajosamente em sua literatura uma percepção a purada e crítica da sociedade.

Tendo como exemplo a audácia de sua avó, que, em pleno século XIX, foi a primeira mulher a se separar legalmente em Saint Louis (Missouri) e, já em idade avançada, tomou-se empresária, Chopin se tornou uma mulher destemida. Viúva a os 32 a nos, teve de se sustentar sozinha, vindo a descobrir sua verdadeira vocação quando passou a escrever regularmente, por indic ação do seu terapeuta, to mando-se, assim, uma exc elente romancista e conquistando sua independência como escritora.

Culpados, mesmo sendo o primeiro romance escrito por Chopin, já a presenta uma maturidade narrativa inegável. Mas o que salta aos olhos do leitor contemporâneo, quando considerado o contexto social à época em que o livro foi public ado, é o questiona mento ostensivo à orientação androcêntrica que vigora va então (e, por que não dizer, vigora até hoje).

Chopin encontrou inúmeras barreiras para publicar suas obras, visto que tocava em temas tabus como divórcio, a lc oolismo, tensões racia is, preconceitos mora is e religiosos, a frivolidade burguesa, etc. Sua escrita era uma afronta à moral estabelecida, na medida em que construía personagens femininasfortes, que representavam o desejo feminino de independência e colocavam em xeque preceitos morais e o comportamento padrão que a sociedade impunha à mulher, comportamento esse objeto incansável da ironia de Chopin.

Identidade e diferença são criações socia is e intelec tua is disputadas nas relações de poder. Na literatura, a representação dos homense das mulheres, e das relações entre eles, tem, há séculos, o caráter de reservar à mulher a condição de inferioridade. Até os dias de hoje, como vimos em resultado recentemente divulgado pela pesquisa desenvolvida na Universidade de Brasília ${ }^{1}$ sobre os personagens da na rrativa brasileira contemporânea, a mulher continua representada em condição marginal. Se a igualdade de gênero depende da superação da disputa por poder que reside na base das relações entre os sexos, podemos entender esse mecanismo como uma estratégia masculina de disputa no campo social, que subentende a desvalorização da quele com quem se disputam posições, no caso, a mulher. Ao criarem repetidamente personagens femininas em situação inferior, os autores (que são em sua maioria homens) normalmente funcionam também, de forma performativa, como agentes produtores de exclusão das mulheres. O que Chopin fazé escapardessa a rimanha, e em lugar de repetir o discurso hegemônico machista, por meio dos personagens que cria, ela estabelece representações que questionam e contestam as posições ocupadas por homens e mulheres na sociedade. A inclusão social da mulher passa por um processo de renovação da sua identidade em todos os setores, inc lusive no campo literário.

Não obstante a censura dos editores, Chop in public ou seu livro com recursos próprios. Teve, por um lado, certo reconhecimento da crític a, que não pôde negarseu talento, maspor outro, pesando muito mais na balança, enfrentou a resistência dos editorese leitores, a inda a rredios 
diante de tamanha ousadia. Os mesmos motivos pelos qua is Chopin foi condena da em sua época hoje the conferem reconhecimento. Sua produção literária é resgatada nos dias atuais justamente por levantar temas que hoje nos são tão caros, tão atuais, especialmente quando se pretende falar da luta da mulher por espaço, reconhec imento, igualdade, mas, sobretud o da reformulação da identidade feminina na sociedade.

Nesse romance Chopin retrata a vida dos crioulos (descendentes de franceses vivend o no Sul dos Estados Unidos) e dos negros que trabalhavam como serviça is nas fazendas da região. Para tanto, a lém de a presentar seu modo de vida, suas tra dições e crenças, ela expõe as peculiaridades lingüístic as de cada grupo reproduzind o sua maneira de falar, elaborada de tal forma que remete à personalidade social e individual de cada um de seus personagens.

De estilo realista, com uma na rativa enxuta, preocupada com descrições dos a mbientes 0 suficiente para colaborar na construção emocionaldospersonagens, a autora mexe com a imaginação do leitor, que toda hora é forçado a preencher os vazios colocados estrategicamente no decorrer do livro. A economia na rativa é um ing rediente que a testa a intenção de forçar o leitorà reflexão. Ele é levado, a todo momento, a fazer elucubrações, a concordar e discordar, a pensarcriticamente sobre o que lê e sobre suas próprias convicções. $E$, se não estiver a tento à ironia, dissimula da muitas vezes, certa mente ca irá na a rmadilha do narrador e será traído por seus próprios preconceitos, poisa capa da moralaqui é colocada ao avesso. 0 que parece certo nos é mostrado factualmente como errado.

A protagonista de Culpados, Thérèse Lafime, viúva a os 30 anos, passa a administra com desenvoltura a plantação de algodão deixada pelo marido. Há que se tercautela desde o início com a construção dessa personagem, pois, a o mesmo tempo em que nos é mostrada como uma mulher diferente, é pela descrição a mbígua do narradorque a vemos: "Thérèse era uma mulher de coração sensível e uma mulhe de visão intelec tual nítida, uma combinação não encontrada com tanta freqüência a ponto de ser comum" (p. 48, grifo nosso). Vemos nessa fra se que, pelo mesmo mecanismo que enaltece Thérèse, ele desmerece, em oposição, uma gama muito maior de mulheres, quase que a firmando que o modelo de mulher comum seria o da mulher sensivel e bura. Não nosenganemos; esse não é um comentá rio simplesmente preconceituoso, mas sim, certamente, vem carregado de tom crítico, como se vê por outras personagense comparações que aparecem no decorrer do livro.

David Hosmer, um empresário divorciado, a parece para propor a Thérèse uma boa oferta em troca do direito de cortar madeira de suas terras por alguns anos. Os dois rapidamente se apaixonam, mas Chopin nos mostra então as limitações de Thérèse, que, ao descobrir que Hosmer era divorciado (de Fanny Larimore, uma jovem alcoólatra e dada a rodadas de diversão com amigos), mostra-se ainda refém de uma moral elevada dema is para se dara o luxo de ser feliz com ele:

- Não pensei que a senhora fosse católica. -

Disse, finalmente virando-se para ela com braç os cruzados.

- Porque o senhor nunca viu nenhum sinal externo. Mas não posso deixá-lo com a impressão errada: a religião não influencia minha opinião neste assunto.

- A senhora acredita, então, que um homem que teve tamanho infortúnio deveria ser privado da felic idade trazida por um segundo casamento?

- Não, nem uma mulher, se estiver de acordo com seu princípio moral, o que eu acredito ser algo peculiarmente pessoal.

- Isto me parece ser um preconceito. Preconceitos podem ser deixados de lado por um esforço da vontade. - Respondeu, segurando-se a um fio de esperança.

- Existem alguns preconceitos que uma mulher nã o pode se darao luxo de abandonar, senhor Hosmer, mesmo pelo preço da felicidade. Por favor, não diga mais nada sobre isso, não pense mais no assunto. - Ela disse com um pouco de arrogância (p. 55-56)

Ainda, a partir desse diálogo podemos refletir sobre a própria questão do divórcio. Chopin, aqui, também subverte o que normalmente se veria à época, que é a mulher divorciada sofrendo o preconceito da sociedade, sofrendo impedimentos morais para poder se casar de novo. Aqui é o homem que aparece como vítima desse preconceito; é o homem que a parece em condição de humilhação.

Ao contrá rio do que possa sugerirà primeira vista, em uma leitura superficial, o tema principal desse romance, apreendido pelo discurso que envolve a história, não é o amor e o sofrimento que este pode causar. Seu tema centralé, antes, a linha tênue que distingue o certo do errado, entendida a partir da perspectiva da religião. A partir dos entraves das convicções mora is de Thérèse, que Chopin põe à prova com o enredo que constrói, é que se dá o questionamento de 
toda uma moral católica vigente, que fomecia uma falsa perspectiva das coisas.

Thérèse, tentando a gir com correção, apesar do a mor que nutria, convence Hosmer a voltar para sua esposa e assumir sua responsabilida de para com ela, o deverde tentar livrá-la de seus vícios. Ele vai buscá-la em Saint Louis e os dois voltam a viver juntos na fazenda, perto da serraria e perto de Thérèse. Apesar de se empenhar na sua tentativa, Hosmer fracassa. Fanny volta a beber, traz de volta o transtomo à vida de Hosmer e, afinal, tragicamente morre afogada em um acidente (morte que teria sido evitada, se tudo tivesse sido deixado como estava).

Hosmer e Thérèse estã 0 , finalmente, livres para viver seu a mor, sem culpa. Mas, naspáginas fina is do livro, eles percebem (assim como nós leitores) claramente que foram vítimas da moral instituída que conta mina suas ações:

- Eu me vi enganada ao seguir o que parecia ser a única coisa certa. Eu sinto como se não houvesse caminho para onde me voltar. Antigos pilares parecem estar se abrindo debaixo de mim. Eram tão seguros antes. Tudo começou, lembra-se, ah, sabe quando deve ter começado. Mas a cha, David, que é certo que devamos encontrarnossa felic idade saída de um passado de dor, pecado e confusão?
- Thérèse. - Disse Hosmer firmemente. - A verdade em sua completude não é dada ao homem conhecer, tal conhecimento, sem dúvida, estaria a lém da capacidade humana. Mas demosum passo nesta direção, sabemos que há podridão e mal no mundo, disfarçados de certo e moral, quando aprendemosa parar nesta luta da vida para questionar (p. 235).

Essas frases pinçadas podem ser tomadas como uma síntese do livro e da intenção viva de Chopin de mostrar que a realidade não é imutável e que é possível elaborar uma outra visão sobre ela. Esc reverum romance assim ta lvez seja o primeiro passo na direção de "escrever" uma outra realidade. São atividades que, de certa forma, se assemelham, se interpenetram e se complementam.

\section{Nota}

1 Pesquisa de mapeamento Personagens da narrativa brasileira contemporânea, do Grupo de Estudos em Literatura Brasileira Contemporânea da UnB. 0 artigo que a nalisa resultados da pesquisa, de autoria da professora doutora Regina Dalcastagnè, pode ser lido no número 26 da revista Estudos de Literatura Brasileira Contemporânea.
Laticia Jensen Eble Universidade de Brasília 